\title{
The Cdc25 protein of Saccharomyces cerevisiae is required for normal glucose transport
}

\author{
Herman H. W. Silljé, ${ }^{1}$ Eelko G. ter Schure, ${ }^{1}$ Arie J. Verkleij, \\ Johannes Boonstra ${ }^{1}$ and $C$. Theo Verrips ${ }^{1,2}$
}
1 Department of Molecular Cell Biology, Utrecht University, Padualaan 8 , $3584 \mathrm{CH}$ Utrecht, The Netherlands
2 Unilever Research Laboratorium Vlaardingen, Olivier van Noortlaan 120 , 3133 AT Vlaardingen, The Netherlands

\author{
Author for correspondence: Herman H. W. Silljé. Tel: +3130 2532598. Fax: +31302513655. \\ e-mail: herman@emsa1.biol.ruu.nl
}

\begin{abstract}
The essential CDC25 gene product of Saccharomyces cerevisiae is the most upstream known component of the RAS/adenylate cyclase pathway. Cdc25 is a GTP-exchange protein involved in activating RAS in response to fermentable carbon sources. In this paper it is reported that the Cdc25 protein, in addition to its stimulatory role in the RAS/adenylate cyclase pathway, regulates glucose transport. Continuous culture studies and glucose uptake experiments showed that the cdc25-1 and the cdc25-5 temperature-sensitive mutants exhibit decreased glucose uptake activity at the restrictive temperature under both repressed and derepressed conditions as compared to the wild-type strain. Because the codc25-1 mutant is not impaired in its CAMP metabolism, it is concluded that this effect on glucose transport is independent of CAMP levels. Furthermore, it is shown that the decrease in glucose uptake activity is not due to a decrease in protein synthesis or to an arrest in the G1 phase of the cell cycle. In addition to a defect in glucose uptake, the cdc25-5 mutant strain exhibited differences in glucose metabolism, probably due to the decreased CAMP level and hence decreased protein kinase A activity. Because the Cdc25 protein is localized at the membrane, these results indicate that Cdc25 is directly involved in glucose transport and may be in direct contact with the glucose transporters.
\end{abstract}

Keywords: Saccharomyces cerevisiae, cdc25 mutants, glucose metabolism, glucose uptake, continuous culture

\section{INTRODUCTION}

The RAS/adenylate cyclase signal transduction pathway plays an important role in the regulation of metabolism and in cell cycle control in the yeast Saccharomyces cerevisiae (Broach, 1991; Thevelein, 1992, 1994). Addition of fermentable carbon sources to a yeast culture growing on a non-fermentable carbon source results in the activation of the RAS/adenylate cyclase pathway, which leads to a transient rise in the intracellular cAMP level (Thevelein, 1992). This in turn results in the liberation of the cAMPdependent protein kinase A (PKA) (Toda et al., 1987a,b) from the regulatory subunit (Toda et al., 1987a) resulting in the activation of PKA. PKA in turn phosphorylates key enzymes of carbon metabolism, for example fructose1,6-bisphosphatase (Rittenhouse et al., 1987) and phos-

Abbreviations: cdc, cell division cycle; PKA, protein kinase A; G6P, glucose 6-phosphate; F1,6BP, fructose 1,6-bisphosphate; GEF, guaninenucleotide-exchange factor. phofructokinase 2 (François et al., 1984), resulting in a net increase in glycolytic activity versus gluconeogenic activity.

The most upstream known activator of the RAS/ adenylate cyclase pathway is the Cdc25 protein (Broek et al., 1987; Camonis et al., 1986; Van Aelst et al., 1991). $\mathrm{Cdc} 25$ is a guanine-nucleotide-exchange factor (GEF) replacing GDP bound to RAS protein by GTP, resulting in the activation of RAS. GTP-activated RAS in turn activates adenylate cyclase, which catalyses the conversion of ATP into cAMP, stimulating PKA activity. The nucleotide sequence of the CDC25 gene codes for a large protein of 1588 or 1589 amino acid residues (Broek et al., 1987; Camonis et al., 1986). Gene disruption and deletion experiments have identified three functional domains of the $\operatorname{Cdc} 25$ protein. The amino-terminal half (the $\alpha$ domain), containing an SH3 domain (Rodaway et al., 1989), is required for efficient sporulation, gluconeogenic functions and glucose-induced cAMP signalling, the carboxy-terminal half (the $\beta 1$-domain), containing the 
guanine-exchange domain, is essential for viability. The last 38 residues of the carboxy terminus, the $\beta 2$-domain, are required for downregulating the cAMP signal transduction pathway (Munder et al., 1988; Munder \& Küntzel, 1989). cdc25 disruption mutants and $c d c 25$ temperature-sensitive mutants have been used to elucidate the function of the Cdc 25 protein. In this study we used the $c d c 25-1$ and the $c d c 25-5$ temperature-sensitive mutants, which have point mutations in the essential $\beta 1$-domain. The $c d c 25-1$ point mutation (Ala-1403 $\rightarrow \mathrm{Val}$ ) is situated within a strongly conserved box found in many GEFs, while the $c d c 25-5$ point mutation (Glu1-328 $\rightarrow$ Lys) is situated between two strongly conserved boxes (Boguski $\&$ McCormick, 1993). In the $c d c 25-5$ mutant this substitution probably results in a change in the $\alpha$-helical structure (Petitjean et al., 1990). This results in the loss of its function in cAMP metabolism after a shift from the permissive temperature to the restrictive temperature (Oehlen et al., 1993; Van Aelst et al., 1991). The substitution in the $c d c 25-1$ mutant is reported not to have an effect on the $\alpha$-helical structure (Petitjean et al., 1990) and cAMP metabolism is still normal in this mutant even at the restrictive temperature (Martegani et al., 1986; Oehlen et al., 1993; Van Aelst et al., 1991). Both mutants arrest in the G1 phase and are impaired in carbon metabolism at the restrictive temperature (Oehlen et al., 1993). This suggests that $\mathrm{Cdc} 25$ has another function in addition to the regulation of adenylate cyclase activity. Because no changes in glycolytic enzyme activities were observed at the restrictive temperature, it has been suggested that this reduction in carbon metabolism is located at the level of uptake (Oehlen et al., 1993).

To gain further insight into the role of the CDC25 gene product in the regulation of glycolytic flux, we have grown the $c d c 25-1$ and $c d c 25-5$ temperature-sensitive mutant strains in glucose-limited continuous cultures. In this way we were able to study physiological parameters such as $\mathrm{O}_{2}$ consumption, $\mathrm{CO}_{2}$ production and concentrations of glycolytic metabolites under well-defined physiological conditions. To investigate the role of the Cdc25 protein in regulating glucose uptake, glucose uptake experiments were performed on batch cultures at both the permissive and the restrictive temperatures.

It is demonstrated that inactivation of the $\mathrm{Cdc} 25$ protein lowers the glucose uptake rate. This effect is independent of cAMP levels and is not due to cell cycle arrest. Because Cdc25 is located at the plasma membrane (Gross et al., 1992), it is suggested that Cdc25 is directly involved in glucose transport, probably via interaction with the glucose transporters.

\section{METHODS}

Strains and growth conditions. Strain JC530-4B and the construction of the isogenic temperature-sensitive strains AP124 and AP127 ( $c d c 25-1$ and $c d c 25-5$, respectively) were described by Petitjean et al. (1990). The strains were grown on minimal medium as described by Sierkstra et al. (1992), with the addition of $600 \mathrm{mg}$ leucine $\mathrm{l}^{-1}, 200 \mathrm{mg}$ histidine $\mathrm{l}^{-1}$ and $200 \mathrm{mg}$ uracil $l^{-1}$. They were grown at a dilution rate of $0 \cdot 1 \mathrm{~h}^{-1}$ at $22^{\circ} \mathrm{C}$ under glucose limitation, with $10 \mathrm{~g}$ glucose $\mathrm{l}^{-1}$ in the feed, in a
Bioflo III fermenter (New Brunswick) with a 21 working volume. The fermenter was connected to a computer and controlled by the advanced fermentation software (AFS) (New Brunswick). The airflow and stirrer speed were set on $21 \mathrm{~min}^{-1}$ and 500 r.p.m., respectively, and the $\mathrm{O}_{2}$ tension in the medium was kept above $50 \%(\mathrm{v} / \mathrm{v})$. The $\mathrm{pH}$ was automatically controlled at a value of 5.0 by the addition of $2 \mathrm{M} \mathrm{NH}_{4} \mathrm{OH}$. $\mathrm{CO}_{2}$ production and $\mathrm{O}_{2}$ consumption were measured on-line by connection of the headspace of the fermenter to a URAS3G carbon dioxide analyser and a MAGNOS4G oxygen analyser (Hartmann \& Braun). For batch growth Yeast Nitrogen Base (YNB) (Sigma) was used, supplemented with the same amounts of leucine, histidine and uracil as indicated above and with either $2 \%(\mathrm{w} / \mathrm{v})$ glucose or $2 \%(\mathrm{w} / \mathrm{v})$ galactose as carbon source.

Glucose pulses. Fifty millilitres of glucose solution ( $2 \mathrm{M})$ was injected directly into the fermenter chamber resulting in a final concentration of glucose in the fermenter of $50-60 \mathrm{mM}$.

Samples. Samples for the determination of residual glucose, extracellular and intracellular metabolites and dry weight were taken from the fermenter as described previously (Sierkstra et al., 1992). Extracts for metabolite determination were prepared as described previously (Sierkstra $e t$ al., 1992). Residual glucose concentrations, and extra- and intracellular metabolites were determined according to Sierkstra et al. (1992), with the modification that all spectrophotometric assays were performed on a Hitachi U2000 spectrophotometer. Total cAMP was measured with the Amersham cAMP kit according to the manufacturer's instructions. Trehalose was measured essentially as described by Neves et al. (1991).

Calculation of glucose fluxes in the fermenter. Under glucoselimited conditions glucose flux was calculated by multiplication of the dilution rate by the difference between the glucose concentration in the feed and the residual glucose concentration in the fermenter divided by the dry weight concentration. After a glucose pulse the glucose flux was calculated by dividing the decrease in residual glucose concentration with time by the dry weight concentration. The glucose flux from the feed into the fermenter was added to this value.

Glucose uptake experiments. These were performed essentially as described by Walsh et al. (1994). Cells were cultured in batch at $22{ }^{\circ} \mathrm{C}$ in YNB with $2 \%$ glucose or $2 \%$ galactose as carbon source. Cultured cells $(80 \mathrm{ml})$ were harvested by filtration at $\mathrm{OD}_{600} 0 \cdot 7$, washed with $100 \mathrm{mM}$ potassium phosphate buffer (pH 6.5) and resuspended in $4 \mathrm{ml}$ of this buffer. Uptake experiments were performed in triplicate with $\left[\mathrm{U}_{-}{ }^{14} \mathrm{C}\right]$ glucose (Amersham) with glucose concentrations of $0.1-250 \mathrm{mM}$ and a specific activity of $0.6-739.8 \mathrm{kBq} \mu \mathrm{mol}^{-1}$. Samples of yeast cells $(100 \mu \mathrm{l})$ were incubated with $100 \mu \mathrm{l}$ twice-concentrated radiolabelled glucose for $5 \mathrm{~s}$ at $22^{\circ} \mathrm{C}$. Quenching, filtration and counting were essentially the same as described by Walsh $e t$ al. (1994). Uptake experiments at $37^{\circ} \mathrm{C}$ were performed with yeast cells which were harvested after a $90 \mathrm{~min}$ incubation at $37^{\circ} \mathrm{C}$. All data were analysed by computer-assisted nonlinear regression by using Enzfitter software. Standard errors were estimated by Enzfitter.

\section{RESULTS}

\section{Glycolytic flux}

The role of the $\mathrm{Cdc} 25$ protein in regulating glycolytic flux was examined in continuous cultures. In this way we were able to change one parameter at a time while all other parameters, such as $\mathrm{pH}$, nutrient concentration and $\mathrm{O}_{2}$ 

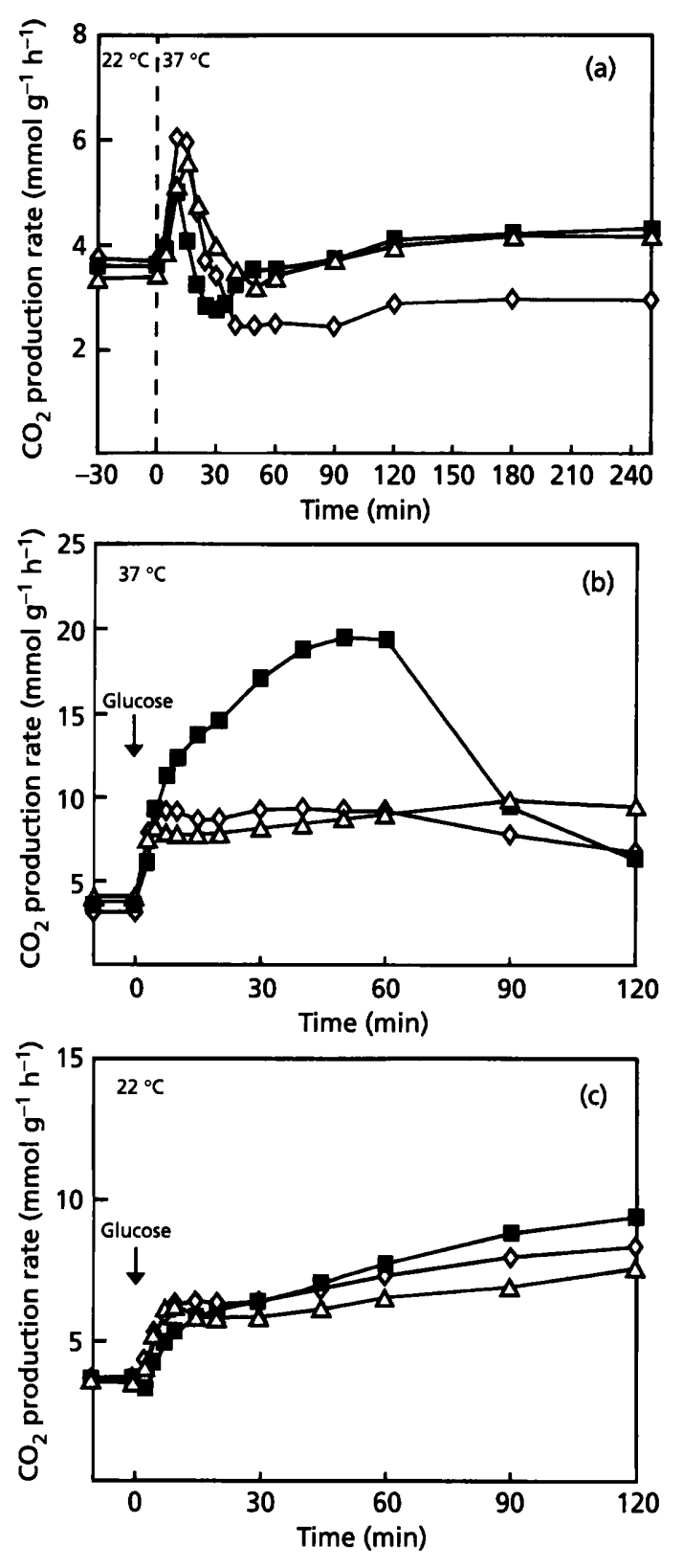

Fig. 1. $\mathrm{CO}_{2}$ production rates of $\mathrm{S}$. cerevisiae grown in glucoselimited continuous cultures at a dilution rate of $0.1 \mathrm{~h}^{-1}$ at $22^{\circ} \mathrm{C}$. $\mathrm{CO}_{2}$ production rates were determined on-line as described in Methods. Measurements were performed twice with similar results. $\square$, Wild-type strain JC530-4B; $\triangle$, cdc25-1 mutant strain AP124; $\diamond, c d c 25-5$ mutant strain AP127. (a) Temperature shift from $22^{\circ} \mathrm{C}$ to $37^{\circ} \mathrm{C}$; (b) addition of $50 \mathrm{mM}$ glucose at $37^{\circ} \mathrm{C}$ (the temperature was raised to $37^{\circ} \mathrm{C} 90 \mathrm{~min}$ before glucose addition); (c) addition of $50 \mathrm{mM}$ glucose at $22^{\circ} \mathrm{C}$.

tension, were kept constant. The $S$. cerevisiae mutant strains $c d c 25-1$ (AP124) and $c d c 25-5$ (AP127), and the isogenic wild-type strain JC530-4B were grown under glucose limitation at a dilution rate of $0.1 \mathrm{~h}^{-1}$ at the permissive temperature of $22^{\circ} \mathrm{C}$. Under these conditions the $\mathrm{CO}_{2}$ production rate of all three strains was approximately $3.5 \mathrm{mmol} \mathrm{g}^{-1} \mathrm{~h}^{-1}$ and the $\mathrm{O}_{2}$ consumption rate was approximately $3.1 \mathrm{mmol} \mathrm{g}^{-1} \mathrm{~h}^{-1}$. Thus the respir- ation coefficient $(\mathrm{RQ})$ was about $1 \cdot 1$, indicating that under these conditions glucose metabolism was totally respiratory. This was supported by the observation that no ethanol, glycerol or acetate were detected in the culture medium (detection limits $0.05 \mathrm{~g} \mathrm{l}^{-1}$ ) (data not shown). Furthermore, the biomass yield under glucose limitation was about about $0.45 \mathrm{~g}$ dry wt $(\mathrm{g} \text { glucose) })^{-1}$ for all strains.

To investigate the effect of altered $\mathrm{Cdc} 25$ function on glucose metabolism, a temperature shift from $22{ }^{\circ} \mathrm{C}$ to $37^{\circ} \mathrm{C}$ was performed. This resulted in a transient increase in $\mathrm{CO}_{2}$ production rate and $\mathrm{O}_{2}$ consumption rate for about $40 \mathrm{~min}$ in all strains (Fig. 1a). The $\mathrm{CO}_{2}$ production rate reached a new steady state value of $3.8 \mathrm{mmol} \mathrm{g}^{-1} \mathrm{~h}^{-1}$ after about $60 \mathrm{~min}$ in the case of the $c d c 25-1$ mutant and wild-type strains and of $2.8 \mathrm{mmol} \mathrm{g}^{-1} \mathrm{~h}^{-1}$ for the $c d c 25-5$ mutant strain. The pattern of increase in $\mathrm{O}_{2}$ consumption rates in all experiments was similar to that of $\mathrm{CO}_{2}$ production rates, giving an almost constant $\mathrm{RQ}$ of about $1 \cdot 1$ (data not shown). This indicates that carbon metabolism remains respiratory under the conditions used. No differences in biomass concentrations between the three strains were observed under these conditions. Thus, under glucose-limited conditions at $37^{\circ} \mathrm{C}$ only the $c d c 25$ 5 mutant exhibited a different $\mathrm{CO}_{2}$ production rate and $\mathrm{O}_{2}$ consumption rate as compared to the wild-type strain. This may be due to a decrease in glucose uptake or glycolysis or to a routeing of glucose metabolites in another direction, for example into reserve carbohydrates.

To establish the response of glucose metabolism to high glucose concentrations at the restrictive temperature, glucose pulses were given as shown in Fig. 1(b). These were given $90 \mathrm{~min}$ after the change in temperature from $22^{\circ} \mathrm{C}$ to $37^{\circ} \mathrm{C}$, at which time the $\mathrm{CO}_{2}$ production rates had reached a new steady value. In this way, the effects of high glucose concentrations on glycolytic flux in the $c d c 25$ mutant strains were not complicated by the initial temperature effects on carbon metabolism. The addition of about $50 \mathrm{mM}$ glucose to the three strains resulted in an immediate increase in the $\mathrm{CO}_{2}$ production rates (Fig. 1b). In the wild-type strain, it increased from 3.8 to $19.4 \mathrm{mmol} \mathrm{g}^{-1} \mathrm{~h}^{-1}$ (a $5 \cdot 1$-fold increase) whereas in the $c d c 25-1$ and $c d c 25-5$ mutant strains it increased from 3.9 to $9.8 \mathrm{mmol} \mathrm{g}^{-1} \mathrm{~h}^{-1}$ (a 2.5 -fold increase) and from 3.0 to $9 \cdot 2 \mathrm{mmol} \mathrm{g}^{-1} \mathrm{~h}^{-1}$ (a $3 \cdot 0$-fold increase), respectively. Thus the increase in $\mathrm{CO}_{2}$ production rate in the $c d c 25$ mutant strains was less than half that in the wild-type strain. Furthermore, the pattern of increase in $\mathrm{CO}_{2}$ production rate in the $c d c 25$ mutant strains differed from that in the wild-type strain. In the $c d c 25$ mutant strains a rapid increase in $\mathrm{CO}_{2}$ production rate for $5 \mathrm{~min}$ was followed by a steady $\mathrm{CO}_{2}$ production rate. The rapid increase in $\mathrm{CO}_{2}$ production rate in the wild-type strain lasted about $10 \mathrm{~min}$ and was followed by a slower increase. After $150 \mathrm{~min}$, the $\mathrm{CO}_{2}$ production rate in the wild-type strain decreased due to the fact that all glucose had been consumed. Compared to the $\mathrm{CO}_{2}$ production rates, $\mathrm{O}_{2}$ consumption rates increased only slightly in the three strains (data not shown). Thus respiratory metabolism remained the same in the three strains, but the increase in fermentative metabolism was almost threefold higher in the wild-type 

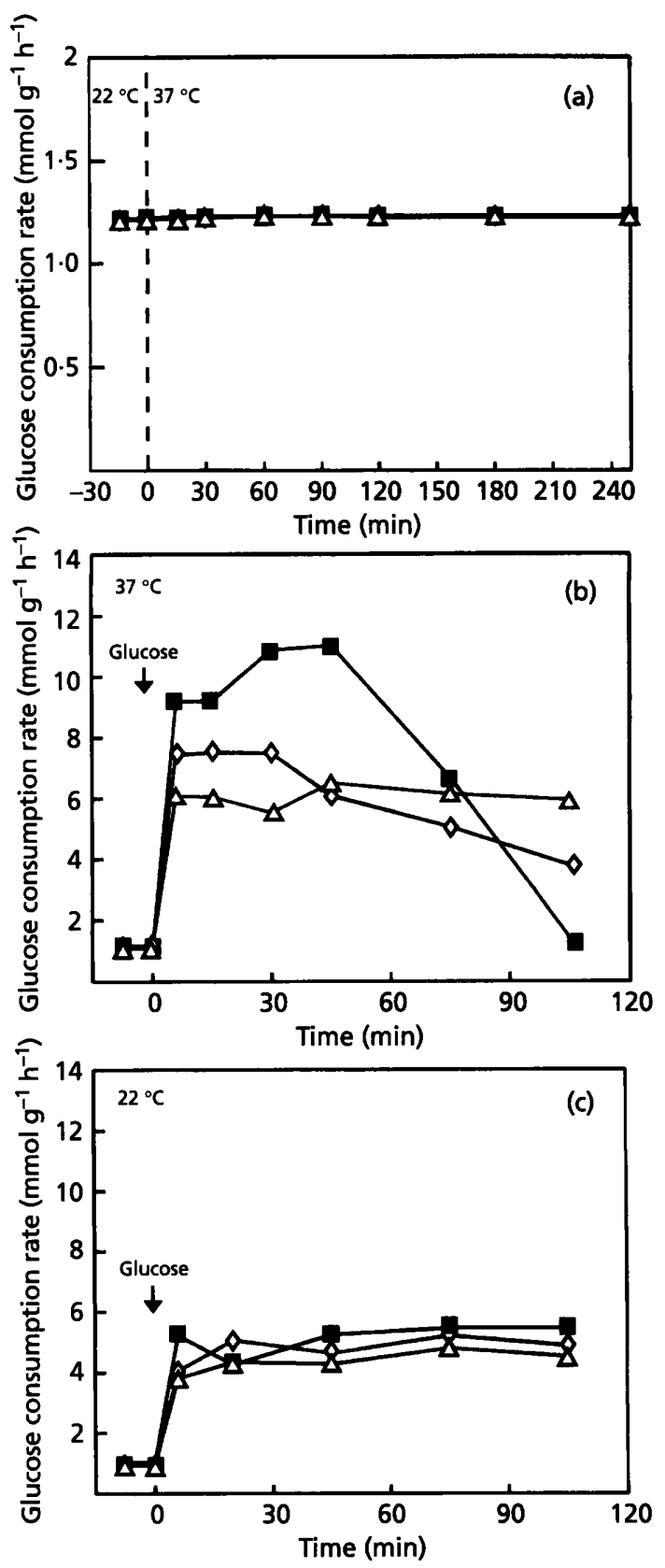

Fig. 2. Glucose consumption rates of $S$. cerevisiae grown in continuous cultures as described in Fig. 1. Glucose consumption rates were calculated from the residual glucose concentrations in the fermenter and the glucose concentration in the medium feed as described in Methods. Residual glucose concentrations were determined in triplicate and mean values were used which had an SE of $<5 \%$. 8 , Wild-type strain JC530-4B; $\triangle$, cdc25-1 mutant strain AP124; $\diamond, c d c 25-5$ mutant strain AP127. (a) Temperature shift from $22^{\circ} \mathrm{C}$ to $37^{\circ} \mathrm{C}$; (b) addition of $50 \mathrm{mM}$ glucose at $37^{\circ} \mathrm{C}$ (the temperature was raised to $37^{\circ} \mathrm{C}$ $90 \mathrm{~min}$ before glucose addition; (c) addition of $50 \mathrm{mM}$ glucose at $22{ }^{\circ} \mathrm{C}$.

than in the $c d c 25-1$ and $c d c 25-5$ mutant strains. A glucose pulse at $22{ }^{\circ} \mathrm{C}$ resulted in almost the same increases in $\mathrm{CO}_{2}$ production rates in all three strains (Fig. 1c). However,
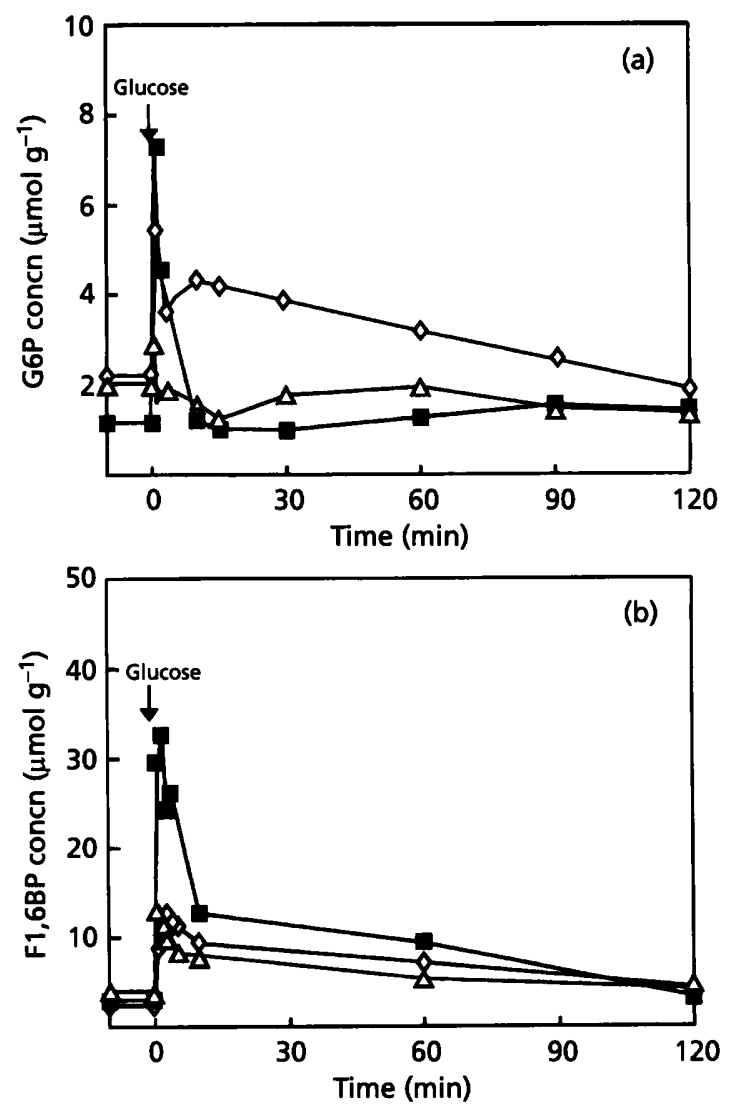

Fig. 3. Effect of glucose on concentrations of G6P (a) and F1,6BP (b) in $S$. cerevisiae grown in glucose-limited continuous cultures at $22^{\circ} \mathrm{C}$. The temperature was raised to $37^{\circ} \mathrm{C} 90 \mathrm{~min}$ before the addition of $50 \mathrm{mM}$ glucose. G6P and F1,6BP concentrations were measured as described in Methods. Values are means of two determinations and the SE was $<15 \%$. $\square$, Wild-type strain JC530-4B; $\triangle$, cdc25-1 mutant strain AP124; $\diamond$, cdc25-5 mutant strain AP127.

the increase in $\mathrm{CO}_{2}$ production was less than at $37^{\circ} \mathrm{C}$ due to the lower temperature. In addition, under these conditions $\mathrm{O}_{2}$ consumption rates increased only slightly as compared to the $\mathrm{CO}_{2}$ production rates (data not shown).

From these results it was concluded that the lower increase in $\mathrm{CO}_{2}$ production rates after the glucose pulse at $37^{\circ} \mathrm{C}$ in the $c d c 25-1$ and $c d c 25-5$ mutant strains as compared to the wild-type strain is caused by the altered functionality of the $\mathrm{Cdc} 25$ protein. To determine if this lower increase was due to a lower glucose uptake rate, residual glucose concentrations in the fermenter were measured and the glucose consumption rates of the cells calculated.

\section{Glucose consumption}

Glucose consumption rates following the temperature shift, and the glucose pulses at $37^{\circ} \mathrm{C}$ and $22^{\circ} \mathrm{C}$ are shown in Fig. 2. At $22^{\circ} \mathrm{C}$, glucose consumption rates were almost the same in the three strains. A switch to the restrictive temperature resulted in a small increase in 
glucose consumption rates in all strains (Fig. 2a). Thus, the lower $\mathrm{CO}_{2}$ production in the $c d c 25-5$ mutant strain at $37^{\circ} \mathrm{C}$ was not due to decreased glucose consumption by the cells.

The glucose consumption rate after a glucose pulse at the restrictive temperature was higher in the wild-type strain as compared to the $c d c 25-1$ and $c d c 25-5$ mutant strains (Fig. $2 \mathrm{~b})$. The glucose consumption rate during the first $20 \mathrm{~min}$ after the pulse, calculated from residual glucose concentrations, was $9 \cdot 20 \mathrm{mmol} \mathrm{g}^{-1} \mathrm{~h}^{-1}$ for the wild-type strain, and 6.07 and $7.48 \mathrm{mmol} \mathrm{g}^{-1} \mathrm{~h}^{-1}$ for the $c d c 25-1$ and $c d c 25$ 5 mutant strains, respectively. It is noteworthy that the glucose consumption rate of the $c d c 25-5$ mutant strain was higher than of the $c d c 25-1$ strain, although this difference was not observed in the $\mathrm{CO}_{2}$ production rates. In the wild-type strain, a further increase in the glucose consumption rate from 9.20 to $11.02 \mathrm{mmol} \mathrm{g}^{-1} \mathrm{~h}^{-1}$ was observed, followed by a decrease due to exhaustion of the glucose in the medium (Fig. 2b). This slow increase correlates with the $\mathrm{CO}_{2}$ production data shown in Fig. $1 \mathrm{~b}$. The slow increase in glucose consumption rate after the initial increase was absent in the $c d c 25$ mutant strains, which is again in accordance with the $\mathrm{CO}_{2}$ production data (Fig. 1b). In the $c d c 25-5$ mutant strain the glucose consumption rate decreased after $30 \mathrm{~min}$, possibly due to the lowered glucose concentration. The difference in glucose consumption rates between the strains after a glucose pulse at $22^{\circ} \mathrm{C}$ was much smaller than at $37^{\circ} \mathrm{C}$ (Fig. 2c). These data demonstrate that the differences in fermentative metabolism (Fig. 1b) after a glucose pulse at $37^{\circ} \mathrm{C}$ are partly due to a lower glucose consumption rate of the $c d c 25-1$ and $c d c 25-5$ mutant strains as compared to the wild-type strain. This could be caused by lower glycolytic activity or by lower glucose uptake activity. To discriminate between these two possibilities glycolytic intermediates were measured.

\section{Concentrations of glucose metabolites, CAMP and ATP}

Following the temperature shift to $37^{\circ} \mathrm{C}$ cAMP levels were analysed to verify the difference between the two $c d c 25$ mutant strains. In both the wild-type and the $c d c 25$ 1 mutant strain an increase in cAMP levels was observed, from 14.3 to $22.8 \mathrm{nmol} \mathrm{g}^{-1}$ and from 16.1 to $25.7 \mathrm{nmol} \mathrm{g}^{-1}$, respectively. In the $c d c 25-5$ mutant however, a decrease in cAMP levels was observed, from 16.3 to $11 \cdot 1 \mathrm{nmol} \mathrm{g}^{-1}$. This is in accordance with most data in the literature (Martegani et al., 1986; Oehlen et al., 1993; Van Aelst et al., 1991), although Petitjean et al. (1990) observed no differences in cAMP levels in these strains.

In order to establish at which level the differences in glycolytic fluxes originated, the concentrations of glycolytic intermediates and ATP were measured. Upon temperature shift to $37{ }^{\circ} \mathrm{C}$ the glucose 6-phosphate (G6P) concentrations decreased from about $4.4 \mu \mathrm{mol} \mathrm{g}^{-1}$ to about $2 \cdot 0 \mu \mathrm{mol} \mathrm{g}^{-1}$ in all three strains. However, no significant changes were found in the concentrations of fructose 1,6-bisphosphate (F1,6BP) $\left(2 \cdot 0 \mu \mathrm{mol} \mathrm{g}^{-1}\right)$, ATP $\left.(4.8 \mu \mathrm{mol} \mathrm{g})^{-1}\right)$ or the citric acid cycle intermediate $\alpha$ - ketoglutarate $\left(33 \mu \mathrm{mol} \mathrm{g}^{-1}\right)$. Because a discrepancy between $\mathrm{CO}_{2}$ production and glucose consumption was observed in the $c d c 25-5$ mutant, trehalose levels were measured in the temperature shift experiment in order to establish if the 'lost' glucose had been routed in other directions, such as the production of reserve carbohydrates. A higher increase in trehalose levels was observed in the $c d c 25-5$ mutant ( 40 to $182 \mu \mathrm{mol} \mathrm{g}^{-1}$ ) compared to the wild-type and the $c d c 25-1$ mutant (21 to $104 \mu \mathrm{mol} \mathrm{g}^{-1}$ and 31 to $98 \mu \mathrm{mol} \mathrm{g}^{-1}$, respectively). Although this difference cannot explain the large difference in $\mathrm{CO}_{2}$ production, it indicates that at least some glucose metabolites are rerouted in the $c d c 25-5$ mutant.

A glucose pulse at $37^{\circ} \mathrm{C}$ resulted in a transient increase in G6P in all three strains, although it was less marked in the $c d c 25-1$ strain (Fig. 3a). However, in the $c d c 25-5$ mutant the G6P concentration remained high, while in the $c d c 25$ 1 mutant and wild-type strain it decreased rapidly to its initial value. The slower decrease in G6P concentration in the $c d c 25-5$ mutant after the glucose pulse at $37^{\circ} \mathrm{C}$ suggests a downstream bottleneck in this mutant. A large transient increase in $\mathrm{F} 1,6 \mathrm{BP}$ concentration, from $2.3 \mu_{\mathrm{mol} \mathrm{g}}{ }^{-1}$ to $31 \cdot 1 \mu \mathrm{mol} \mathrm{g}{ }^{-1}$, was observed in the wild-type strain (Fig. $3 \mathrm{~b})$. The increase in F1,6BP level was lower in the mutant strains, from about $2.3 \mu \mathrm{mol} \mathrm{g}^{-1}$ to about $13.3 \mu \mathrm{mol} \mathrm{g}^{-1}$ (Fig. 3b). The higher transient increase in F1,6BP concentration in the wild-type strain after the glucose pulse at $37^{\circ} \mathrm{C}$ suggests that the initial glucose influx in this strain is higher than in the $c d c 25$ mutant strains. This observation is supported by the glucose consumption rate results presented in Fig. 2(b). An increase in $\alpha$ ketoglutarate concentration was observed in all three strains $10 \mathrm{~min}$ after the giucose pulses, while the ATP levels remained constant except for a transient decrease immediately after the pulse (data not shown). The three strains showed no differences in G6P, ATP or $\alpha$ ketoglutarate concentrations following addition of glucose at $22{ }^{\circ} \mathrm{C}$ (data not shown). Only the F1,6BP concentration exhibited a transient increase from about $3.0 \mu \mathrm{mol} \mathrm{g}^{-1}$ to about $26.7 \mu \mathrm{mol} \mathrm{g}^{-1}$ in all three strains.

These results suggest that the lower glucose metabolism in the mutant strains after the glucose pulse at $37^{\circ} \mathrm{C}$ is at least partially located at the level of glucose uptake. Furthermore, they show that in the cdc25-5 mutant glycolytic differences are present in addition to a glucose uptake defect. To demonstrate that the lower glucose consumption rate in the $c d c 25$ mutant strains was due to a lower glucose uptake activity, uptake experiments were performed.

\section{Glucose uptake experiments}

These were performed in batch cultures growing on either $2 \%$ glucose or $2 \%$ galactose. In this way we were able to investigate glucose uptake of glucose-repressed cells (grown on glucose) and glucose-derepressed cells (grown on galactose). Glucose uptake was measured over $5 \mathrm{~s}$. During this time period glucose uptake is linear under all experimental conditions. 


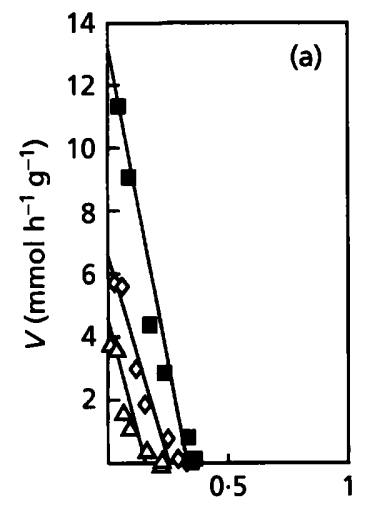

VIS $\left(\mathrm{mmol} \mathrm{h}^{-1} \mathrm{~g}^{-1} \mathrm{mM}^{-1}\right)$

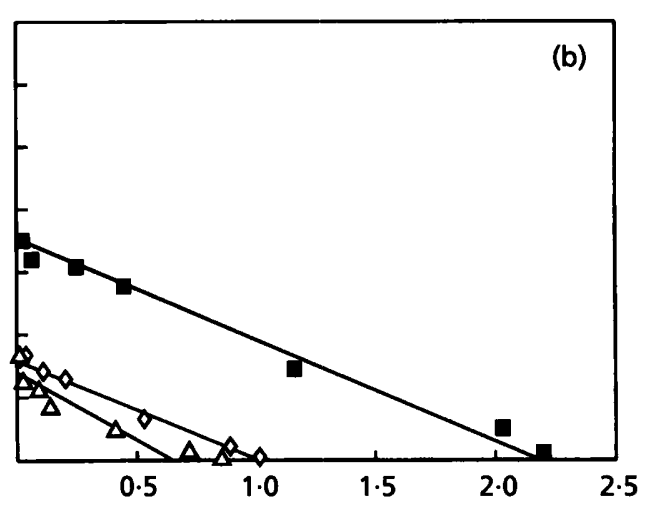

VIS (mmol h-1 $\left.\mathrm{g}^{-1} \mathrm{mM}^{-1}\right)$
Fig. 4. Glucose transport of $S$. cerevisiae under repressed and derepressed conditions at $37^{\circ} \mathrm{C}$. Transport was assessed by measuring the amount of radiolabelled glucose taken up by the cells in $5 \mathrm{~s}$, as described in Methods. Different concentrations of radiolabelled [U${ }^{14} \mathrm{C}$ glucose were used. Cells growing at $22^{\circ} \mathrm{C}$ were shifted to $37^{\circ} \mathrm{C} 90 \mathrm{~min}$ before the glucose uptake experiments and results are presented as Eadie-Hofstee plots. Wild-type strain JC530-4B; $\triangle$, cdc25-1 mutant strain AP124; $\diamond$, cdc25-5 mutant strain AP127. (a) Glucose-repressed cells grown on $2 \%$ glucose; (b) glucosederepressed cells grown on $2 \%$ galactose.

Table 1. Glucose uptake characteristics of S. cerevisiae at $22^{\circ} \mathrm{C}$ and $37^{\circ} \mathrm{C}$

The results are means of at least three determinations \pm SEM.

\begin{tabular}{|c|c|c|c|c|}
\hline \multirow[t]{2}{*}{ Strain } & \multicolumn{2}{|l|}{$22^{\circ} \mathrm{C}^{*}$} & \multicolumn{2}{|l|}{$37^{\circ} \mathrm{C} \dagger$} \\
\hline & $V_{\max }\left(\mathrm{mmol} \mathrm{h}^{-1} \mathrm{~g}^{-1}\right)$ & $K_{m}(\mathrm{mM})$ & $V_{\max }\left(\mathrm{mmol} \mathrm{h}^{-1} \mathrm{~g}^{-1}\right)$ & $K_{\mathrm{m}}(\mathrm{mM})$ \\
\hline \multicolumn{5}{|c|}{ (a) Glucose-repressed cells (grown on $2 \%$ glucose) } \\
\hline JC530-4B (wild-type) & $7 \cdot 07 \pm 0.24$ & $24 \cdot 0 \pm 4 \cdot 1$ & $13 \cdot 54 \pm 0.54$ & $49 \cdot 1 \pm 5 \cdot 8$ \\
\hline $\mathrm{JC} 530-4 \mathrm{~B}+$ cyc $\ddagger$ & ND & ND & $12 \cdot 37 \pm 0 \cdot 15$ & $40 \cdot 1 \pm 1 \cdot 6$ \\
\hline AP124 (cdc25-1) & $4 \cdot 39 \pm 0 \cdot 20$ & $27 \cdot 8 \pm 4 \cdot 3$ & $4 \cdot 57 \pm 0 \cdot 24$ & $36 \cdot 4 \pm 5 \cdot 8$ \\
\hline AP127 (cdc25-5) & $5 \cdot 17 \pm 0 \cdot 17$ & $20 \cdot 8 \pm 2 \cdot 5$ & $6 \cdot 51 \pm 0 \cdot 37$ & $27 \cdot 7 \pm 5 \cdot 1$ \\
\hline \multicolumn{5}{|c|}{ (b) Glucose-derepressed cells (grown on $2 \%$ galactose) } \\
\hline JC530-4B (wild-type) & $3.45 \pm 0.06$ & $2 \cdot 5 \pm 0 \cdot 2$ & $6 \cdot 90 \pm 0 \cdot 11$ & $3 \cdot 2 \pm 0 \cdot 3$ \\
\hline $\mathrm{AP} 124(c d c 25-1)$ & $2 \cdot 07 \pm 0 \cdot 12$ & $2 \cdot 6 \pm 0.9$ & $3.07 \pm 0.17$ & $7 \cdot 2 \pm 1 \cdot 6$ \\
\hline AP127 $(c d c 25-5)$ & $2 \cdot 46 \pm 0.04$ & $2 \cdot 7 \pm 0 \cdot 3$ & $3.33 \pm 0.08$ & $3.8 \pm 0.5$ \\
\hline
\end{tabular}

ND, Not determined.

* Cells were grown as described in Methods.

† Cells were grown at $22^{\circ} \mathrm{C}$ as described in Methods then shifted to $37^{\circ} \mathrm{C}$ for $90 \mathrm{~min}$.

$\ddagger$ Cycloheximide $\left(0 \cdot 1 \mu \mathrm{g} \mathrm{ml}^{-1}\right)$ was added at the time that the cells were shifted from $22^{\circ} \mathrm{C}$ to $37^{\circ} \mathrm{C}$.

The results of the glucose uptake experiments under repressed and derepressed conditions at $37^{\circ} \mathrm{C}$ are shown as Eadie-Hofstee plots in Fig. 4(a) and 4(b), respectively. Under both conditions a linear relation between the points was observed with the difference between repressed and derepressed states visible as differences in slopes of the lines. Furthermore it is clear that under both conditions the apparent $V_{\max }$ values of the $c d c 25$ mutant strains are lower than in the wild-type strain. From Fig. 4 the apparent $K_{\mathrm{m}}$ and $V_{\max }$ values were calculated and are presented in Table 1, together with the apparent $V_{\max }$ and $K_{\mathrm{m}}$ values obtained under the same conditions at $22{ }^{\circ} \mathrm{C}$. At $22{ }^{\circ} \mathrm{C}$ no differences in apparent $K_{\mathrm{m}}$ values were observed between the strains under both growth conditions. The apparent $V_{\max }$ value for glucose transport at $22{ }^{\circ} \mathrm{C}$ was however about 1.5 -fold higher in the wild-type strains as compared to the $c d c 25$ mutant strains under repressed and derepressed conditions. This indicates that at $22{ }^{\circ} \mathrm{C}$ glucose transport was affected by both $c d c 25$ point mutations. At $37^{\circ} \mathrm{C}$ the apparent $K_{\mathrm{m}}$ of the wild-type strain under repressed conditions was higher than that of the mutant strains. Under derepressed conditions this was not observed, but under these conditions the apparent $K_{\mathrm{m}}$ value of the $c d c 25-1$ mutant was about twofold higher as compared to the wild-type and the $c d c 25-5$ strain. At $37^{\circ} \mathrm{C}$ the apparent $V_{\max }$ value for glucose transport was about 2 - to 3-fold higher in the wild-type strain as compared to the $c d c 25$ mutant strains under both repressed and derepressed conditions. Furthermore, under all conditions the apparent $V_{\max }$ values of the $c d c 25-1$ mutant strain were lower than in the $c d c 25-5$ mutant strain, indicating allele-specific differences. From these results it is clear that inactivation of the $\mathrm{Cdc} 25$ protein results in a lowered glucose uptake rate. The effects were also observed at the permissive temperature, although were less marked. That these differences at $22{ }^{\circ} \mathrm{C}$ were not observed after the glucose pulses to the fermenter cultures is probably due to other downstream glycolytic reactions 
Table 2. Glucose uptake of $S$. cerevisae after a shift to $37^{\circ} \mathrm{C}$ for $90 \mathrm{~min}$ and subsequent shift back to $22^{\circ} \mathrm{C}$

Uptake rates (expressed in $\mathrm{mmol} \mathrm{h}{ }^{-1} \mathrm{~g}^{-1}$ ) were measured at a final $\left[\mathrm{U}-{ }^{14} \mathrm{C}\right]$ glucose concentration of $100 \mathrm{mM}$ for $5 \mathrm{~s}$. The results are means of three determinations \pm SEM.

\begin{tabular}{|c|c|c|c|c|}
\hline \multirow[t]{3}{*}{ Strain } & \multirow{3}{*}{$\begin{array}{c}\text { Before shift } \\
\text { to } 37^{\circ} \mathrm{C}\end{array}$} & \multicolumn{3}{|c|}{ After shift to $37^{\circ} \mathrm{C}$} \\
\hline & & \multicolumn{3}{|c|}{ Time (min) at $22^{\circ} \mathrm{C}:$} \\
\hline & & 15 & 60 & $60+$ cyc* \\
\hline JC530-4B (wild-type) & $5 \cdot 19 \pm 0 \cdot 01$ & $5.09 \pm 0.00$ & $4.95 \pm 0.02$ & $3.57 \pm 0.02$ \\
\hline AP124 $(c d c 25-1)$ & $3 \cdot 23 \pm 0 \cdot 00$ & $2 \cdot 04 \pm 0.02$ & $2 \cdot 90 \pm 0 \cdot 17$ & $0.85 \pm 0.01$ \\
\hline $\mathrm{AP} 127(c d c 25-5)$ & $4 \cdot 26 \pm 0 \cdot 03$ & $2 \cdot 10 \pm 0 \cdot 01$ & $4 \cdot 51 \pm 0 \cdot 00$ & $1 \cdot 50 \pm 0.04$ \\
\hline
\end{tabular}

* Cycloheximide $\left(10 \mu \mathrm{g} \mathrm{ml}^{-1}\right)$ was added at the time the cells were shifted from $37^{\circ} \mathrm{C}$ back to $22^{\circ} \mathrm{C}$.

which are rate-limiting at this low temperature. This conclusion is supported by the fact that at $22{ }^{\circ} \mathrm{C}$ G6P levels are higher than at $37^{\circ} \mathrm{C}$.

To check that the observed differences were not due to an arrest in $\mathrm{G} 1$ in the $c d c 25$ mutant strains, the protein synthesis inhibitor cycloheximide was added to the wildtype strain at a concentration of $0 \cdot 1 \mu \mathrm{g} \mathrm{ml}^{-1}$. This inhibitor was added at the time the cells were shifted from $22{ }^{\circ} \mathrm{C}$ to $37^{\circ} \mathrm{C}$. The addition caused an arrest in the G1 phase of the cell cycle but had only a minor effect on the apparent $V_{\max }$ of glucose uptake, indicating that cell cycle arrest is not the cause of the lowered glucose uptake in the cdc25 mutant strains. Complete inhibition of protein synthesis in the wild-type strain by addition of $10 \mu \mathrm{g} \mathrm{ml}^{-1}$ cycloheximide during the shift to $37^{\circ} \mathrm{C}$ for $90 \mathrm{~min}$ resulted in a decrease in apparent $V_{\max }$ to $10.49 \mathrm{mmol} \mathrm{h}^{-1} \mathrm{~g}^{-1}$. Thus the glucose transporters have a relatively long half-life, indicating that the decrease in glucose transport in the mutant strains cannot be due to a decrease in expression of the glucose transporters. Therefore, the most likely explanation for the decreased glucose uptake in the $c d c 25$ mutants is that Cdc25 itself is directly involved in the regulation of glucose uptake. To examine whether, following a shift to $37^{\circ} \mathrm{C}$ for $90 \mathrm{~min}$ and subsequent shift back to $22^{\circ} \mathrm{C}$, protein synthesis is necessary in the $c d c 25$ mutant strains for glucose uptake activity to return to original levels, samples were taken after 15 and $60 \mathrm{~min}$ and glucose uptake activity measured using $100 \mathrm{mM}$ glucose (Table 2). In addition, a sample of the cells was treated with cycloheximide at the time of the shift back to $22{ }^{\circ} \mathrm{C}$ and glucose uptake activity measured after $60 \mathrm{~min}$ incubation (Table 2). Fifteen minutes after the shift back to $22{ }^{\circ} \mathrm{C}$ glucose uptake was decreased in the $c d c 25$ mutant strains, but not in the wild-type strain. After $60 \mathrm{~min}$ incubation at $22{ }^{\circ} \mathrm{C}$, glucose uptake activity in the mutant strains had almost returned to the original levels. Cycloheximide addition prevented this return of normal glucose uptake activities. Although cycloheximide also affected glucose uptake in the wild-type, these results indicate that protein synthesis is necessary to regain normal glucose uptake activity in the $c d c 25$ mutant strains after the shift to $37^{\circ} \mathrm{C}$. At this time we are not able to distinguish whether new glucose transporters have to be synthesized or new Cdc25 protein.

All the data presented show that the decreased glycolytic flux at the restrictive temperature in the $c d c 25$ mutant strains is at least partly due to decreased glucose uptake, and that this is not due to a decrease in protein synthesis or to G1 arrest. Since in the $c d c 25-1$ mutant cAMP levels are still normal at the restrictive temperature, the observed effects are independent of PKA activity.

\section{DISCUSSION}

To investigate the role of the $\mathrm{Cdc} 25$ protein in regulating carbon metabolism we have grown two temperaturesensitive $c d c 25$ mutant strains, $c d c 25-1$ and $c d c 25-5$, and the isogenic wild-type under glucose-limited conditions in continuous cultures.

In the $c d c 25-5$ mutant, after a glucose pulse at the restrictive temperature metabolic differences compared to the wild-type strain were observed. The glucose consumption rate and $\mathrm{CO}_{2}$ production rate were lower in the $c d c 25-5$ mutant as compared to the wild-type strain. Furthermore, under this condition G6P levels were higher in the $c d c 25-5$ mutant as compared to the other strains. It is likely that due to the impaired cAMP metabolism in the $c d c 25-5$ mutant, glycolysis is not activated upon glucose addition, resulting in higher G6P levels and a change in glucose metabolism. Also under glucose-limited conditions at the restrictive temperature, the $c d c 25-5$ mutant exhibited a change in carbon metabolism, which was manifested by the lowered $\mathrm{CO}_{2}$ production rate. Under this condition no difference in glucose uptake rate or concentrations of glycolytic intermediates were observed, but a greater increase in trehalose concentrations was observed in the $c d c 25-5$ mutant as compared to the other strains. Although the increase in trehalose concentration cannot solely account for the lower $\mathrm{CO}_{2}$ production rate, it suggests that at least some glucose is routed in directions other than glycolysis.

In the $c d c 25-1$ mutant, the glucose consumption rate was 
also lower as compared to the wild-type strain after the glucose pulse at the restrictive temperature. In this mutant, no differences in concentrations of glycolytic intermediates such as G6P were observed as compared to the wild-type strain. This indicates that in this mutant glucose uptake but not glucose metabolism was affected. These data are in accordance with those reported by Oehlen et al. (1993) who suggested that metabolism in these mutants is affected in the first steps of glycolysis or at the level of uptake. It should be noted that the pattern of $\mathrm{CO}_{2}$ production rate and glucose consumption rate differed between the wild-type strain and the $c d c 25$ mutant strains after a glucose pulse at the restrictive temperature. Possibly, the regulation of glucose uptake in the $c d c 25$ mutant strains is affected in such a way that they cannot respond properly to changing glucose concentrations.

Glucose uptake experiments were performed to establish how glucose transport was affected in the strains. It must be emphasized that the glucose uptake system in $S$. cerevisiae is very complex, consisting of about 14 putative glucose transporters, of which at least 7 are transporters (Reifenberger et al., 1995). The expression of these transporters is strongly regulated by environmental conditions (Özcan \& Johnston, 1995). Thus, in the glucose uptake experiments not one transporter was being studied, but a large number of transporters, together resulting in average apparent $K_{\mathrm{m}}$ and $V_{\max }$ values of the transporters present under those particular conditions. The glucose uptake experiments with batch cultures revealed that at $37^{\circ} \mathrm{C}$ the $c d c 25-1$ and $c d c 25-5$ mutant strains have a lower apparent $V_{\max }$ for glucose transport as compared to the wild-type strain under both repressed and derepressed conditions. Under both conditions, the $c d c 25-1$ mutant strain has an even lower apparent $V_{\max }$ than the $c d c 25-5$ mutant strain, which is in agreement with the lower glucose consumption rate in the $c d c 25-1$ mutant strain after the glucose pulses in the fermenter at $37^{\circ} \mathrm{C}$. The results of the glucose uptake experiments clearly indicate that the lower glucose consumption rate in the $c d c 25$ mutant strains after a glucose pulse at $37^{\circ} \mathrm{C}$ is a result of a decreased apparent $V_{\max }$ in the mutant strains as compared to the wild-type strain. Addition of the protein synthesis inhibitor cycloheximide $\left(0 \cdot 1 \mu \mathrm{g} \mathrm{ml}^{-1}\right)$ to the wild-type strain resulted in G1 arrest, but had only a minor effect on glucose uptake activity. It is therefore concluded that the decrease in glucose uptake activity in the $c d c 25$ mutant strains is a direct result of a change in Cdc25 activity and is not due to an arrest in G1. Also, a complete inhibition of protein synthesis did not result in a decrease in glucose uptake in the wild-type strain to the same extent as in the $c d c 25$ mutant strains. This indicates that a possible change in expression of the $H X T$ genes cannot be the only reason for the decreased glucose uptake activity in the $c d c 25$ mutant strains, due to the relatively long half-life of the transporters. It is therefore expected that the decreased glucose uptake activity in the mutants is due to a direct effect of $\mathrm{Cdc} 25$ on glucose transport. After a shift to the restrictive temperature, protein synthesis was necessary to regain the normal uptake levels in the $c d c 25$ mutants. However, it is not clear if this is due to a decreased level of glucose transporters, or to the fact that the mutant $\mathrm{Cdc} 25$ protein cannot refold properly. At this time we are not able to resolve this question owing to lack of antibodies against the different glucose transporters and $\mathrm{Cdc} 25$. If the decrease in glucose transport activity is due to a breakdown of transporters, this is specific for glucose transporters, because no changes in the activities of other glycolytic enzymes, such as hexokinases, have been observed in these mutants (Oehlen et al., 1993). If this is the case than Cdc25 may have a stabilizing effect on the glucose transporters.

Although less marked, the apparent $V_{\max }$ values of the glucose uptake system of the $c d c 25-1$ mutant strain and, to a lesser extent, the $c d c 25-5$ mutant strain were also lower at the permissive temperature compared with the wild-type strain. These differences between the strains were not observed in the fermenter studies, probably owing to the low temperature at which downstream glucose metabolism is limiting but glucose uptake is not. This is in agreement with the higher G6P levels observed at $22{ }^{\circ} \mathrm{C}$ as compared to $37^{\circ} \mathrm{C}$.

The results indicate that the $\mathrm{Cdc} 25$ protein is involved in glucose transport, in addition to its role in cAMP control and cell cycle regulation. In the $c d c 25-1$ mutant strain only glucose uptake is affected, while in the cdc25-5 mutant strain metabolism is also affected. The decrease in glucose uptake activity in the $c d c 25$ mutant strains is not due to a decreased protein synthesis rate or G1 arrest in these strains. In the $c d c 25-1$ mutant strain the cAMP levels are still normal at the restrictive temperature. Therefore it is concluded that the decrease in the glucose uptake activity is independent of the cAMP levels and hence PKA activity. Thus $\mathrm{Cdc} 25$ is involved in glucose uptake, cell cycle progression and cAMP metabolism, but these processes seem to be independently regulated by $\mathrm{Cdc} 25$. It has been shown that in a $c d c 35$ (encoding adenylate cyclase) temperature-sensitive mutant with normal cAMP levels at the restrictive temperature, glucose uptake is decreased (Oehlen et al., 1994), suggesting that Cdc25 and $\mathrm{Cdc} 35$ themselves are required for normal glucose uptake. Gross et al. (1992) have demonstrated that the Cdc25 protein is attached to the membrane cytoskeleton and is associated with the RAS proteins and adenylate cyclase. The RAS proteins are also attached to the membrane, via a farnesyl and a palmitoyl chain. Therefore the total complex of Cdc25/RAS/adenylate cyclase is situated at the plasma membrane and is thus in close vicinity, perhaps in direct contact, with the glucose transporter molecules or hexokinases. This increases the probability that the Cdc25/RAS/adenylate cyclase complex has a direct effect on glucose uptake and vice versa. The presence of multiple glucose transporters in $S$. cerevisiae explains why no other upstream activators of the Cdc25/RAS/adenylate cyclase pathway have been found. Also, in higher eukaryotes many GEF-like proteins are activated by receptors located in the plasma membrane. So, in an analogous situation, the glucose transporters in $S$. cerevisiae may also function as glucose sensors regulating the $\mathrm{Cdc} 25 / \mathrm{RAS} /$ adenylate cyclase pathway. 


\section{ACKNOWLEDGEMENTS}

We wish to thank Professor J. M. Thevelein for provision of the yeast strains.

\section{REFERENCES}

Boguski, M. S. \& McCormick, F. (1993). Proteins regulating Ras and its relatives. Nature 366, 643-653.

Broach, J. R. (1991). RAS genes in Saccharomyces cerevisiae: signal transduction in search of a pathway. Trends Genet 7, 28-32.

Broek, D., Toda, T., Michaeli, T., Levin, L., Birchmeier, C., Zoller, M., Powers, S. \& Wigler, M. (1987). The S. cerevisiae cdc25 gene product regulates the RAS/adenylate cyclase pathway. Cell 48, 789-799.

Camonis, J. H., Kalékine, M., Gondré, B., Garreau, H., BoyMarcotte, E. \& Jacquet, M. (1986). Characterization, cloning and sequence analysis of the CDC25 gene which controls the cAMP level of Saccharomyces cerevisiae. EMBO J 5, 375-380.

Francois, J., Van Schaftingen, E. \& Hers, H. G. (1984). The mechanism by which glucose increases fructose-2,6-bisphosphate concentration in Saccharomyces cerevisiae. Eur J Biochem 145, 187-193.

Gross, E., Marbach, I., Engelberg, D., Segal, M., Simchen, G. \& Levitzki, A. (1992). Anti-Cdc25 antibodies inhibit guanyl nucleotide-dependent adenylyl cyclase of Saccharomyces cerevisiae and cross-react with a 150 -kilodalton mammalian protein. Mol Cell Biol 12, 2653-2661.

Martegani, E., Baroni, M. \& Vanoni, M. (1986). Interaction of cAMP with the CDC25-mediated step in the cell cycle of budding yeast. Exp Cell Res 162, 544-548.

Munder, T. \& Küntzel, H. (1989). Glucose-induced cAMP signalling in Saccharomyces cerevisiae is mediated by the CDC25 protein. FEBS Lett 242, 341-345.

Munder, T., Mink, M. \& Kuntzel, H. (1988). Domains of the Saccharomyces cerevisiae CDC25 gene controlling mitosis and meiosis. Mol Gen Genet 214, 271-277.

Neves, J. N., Jorge, J. A., Francois, J. M. \& Terenzi, H. F. (1991). Effects of heat shock on the level of trehalose and glycogen, and on the induction of thermotolerance in Neurospora crassa. FEBS Lett 283, 19-22.

Oehlen, L. J. W. M., Scholte, M. E., De Koning, W. \& van Dam, K. (1993). Inactivation of the $C D C 25$ gene product in Saccharomyces cerevisiae leads to a decrease in glycolytic activity which is independent from cAMP levels. J Gen Microbiol 139, 2091-2100.

Oehlen, L. J. W. M., Scholte, M. E., de Koning, W. \& van Dam, K.
(1994). Decrease in glycolytic flux in Saccharomyces cerevisiae cdc35-1 cells at restrictive temperature correlates with a decrease in glucose transport. Microbiol 140, 1891-1898.

Özcan, S. \& Johnston, M. (1995). Three different regulatory mechanisms enable yeast hexose transporter ( $H X T$ ) genes to be induced by different levels of glucose. Mol Cell Biol 15, 1564-1572.

Petitjean, A., Hilger, F. \& Tatchell, K. (1990). Comparison of thermosensitive alleles of the CDC25 gene involved in the cAMP metabolism of Saccharomyces cerevisiae. Genetics 124, 797-806.

Reifenberger, E., Freidel, K. \& Ciriacy, M. (1995). Identification of novel HXT genes in Saccharomyces cerevisiae reveals the impact of individual hexose transporters on glycolytic flux. Mol Microbiol 16, 157-167.

Rittenhouse, J., Moberly, L. \& Marcus, F. (1987). Phosphorylation in vivo of yeast (Saccharomyces cerevisiae) fructose-1,6-bisphophatase at the cyclic AMP-dependent site. J Biol Chem 262, 10114-10119.

Rodaway, A. R. F., Sternberg, M. J. E. \& Bentley, D. L. (1989). Similarity in membrane proteins. Science 342, 624.

Sierkstra, L. N., Verbakel, J. M. A. \& Verrips, C. T. (1992). Analysis of transcription and translation of glycolytic enzymes in glucoselimited continuous cultures of Saccharomyces cerevisiae. J Gen Microbiol 138, 2559-2566.

Thevelein, J. M. (1992). The RAS-adenylate cyclase pathway and cell cycle control in Saccharomyces cerevisiae. Antonie Leeuwenboek 62, 109-130.

Thevelein, J. M. (1994). Signal transduction in yeast. Yeast 10 , 1753-1790.

Toda, T., Cameron, S., Sass, P., Zoller, M., Scott, J. D., McMullen, B., Hurwitz, M., Krebs, E. G. \& Wigler, M. (1987a). Cloning and characterization of $B C Y 1$, a locus encoding a regulatory subunit of cAMP dependent protein kinase in yeast. Mol Cell Biol 7, 1371-1377.

Toda, T., Cameron, S., Sass, P., Zoller, M. \& Wigler, M. (1987b). Three different genes in $S$. cerevisiae encode the catalytic subunits of the cAMP-dependent protein kinase. Cell 50, 277-287.

Van Aelst, L., Jans, A.W. H. \& Thevelein, J. M. (1991). Involvement of the $C D C 25$ gene product in the signal transmission pathway of the glucose-induced RAS-mediated cAMP signal in the yeast Saccharomyces cerevisiae. J Gen Microbiol 137, 341-349.

Walsh, M. C., Smits, H. P., Scholte, M. \& van Dam, K. (1994). Affinity of glucose transport in Saccharomyces cerevisiae is modulated during growth on glucose. J Bacteriol 176, 953-958.

Received 7 February 1996; revised 19 February 1996; accepted 20 February 1996. 